\title{
Perceptions of strength training practitioners on nutritional aspects Strength Training and Nutrition
}

\begin{abstract}
This study aims to identify the knowledge that strength training practitioners have about nutritional aspects. This research presents a qualitative approach to the data, despite the possibility of providing quantitative information, aiming to discover the reality of the dietary conduct adopted by the subjects participating in the sample. The sample consisted of 20 resistance training practitioners, of both sexes, aged between 16 and 45 . We used two questionnaires in data collection. The findings show that $85 \%$ of the subjects participants never obtained recommendations nutritionally supported by nutritionists, and $67 \%$ supplement without monitoring. The participants expressed knowledge of moderate nutritional status - the results point for a probable correlation between the level of knowledge and education.
\end{abstract}

Keywords: nutrition, physical education, professional practice, health, supplement
Volume 14 Issue 5 - 202I

\author{
Monteiro Gomes, Carlos Alberto Figueiredo \\ da Silva \\ 'Department of Nutrition, Centro Universitário Augusto Motta, \\ Brazil \\ ${ }^{2}$ Department of Nutrition, Universidade Salgado de Oliveira, \\ Brazil
}

Correspondence: Carlos Alberto Figueiredo da Silva,

Universidade Salgado de Oliveira, Av. Alberto Francisco Torres,

Niterói, RJ, B Brazil, Tel 00521993283350 ,

Email ca.figueiredo@yahoo.com.br

Received: January II, 2020 | Published: October II, 202 I

\section{Introduction}

The demand for physical activity continues to grow, as people are increasingly aware of how crucial it is for health and quality of life. However, the desire for the aesthetic results that such activities provide is why it has most elevated the demand for gyms or leisure and gym centers. ${ }^{1}$

Most strength training practitioners want a healthy and aesthetically beautiful body. ${ }^{2}$ To obtain such a result, many practitioners end up acquiring a certain compulsion for the exacerbated practice of resistance training. ${ }^{3}$ The muscular functioning under effort or not, depends on typical conditions and needs adapting the food to the individual's energy expenditure. ${ }^{4}$

Since strength training, as physical activity, promotes a marked increase in lean mass ${ }^{5}$ in the same way, the management of the energy balance is of fundamental relevance, as the exercise itself increases energy expenditure/calorie and, consequently, the need for compensation through nutrients, and thus supply the energy expenditure affected by training. ${ }^{6}$

The energy balance is the association between intake and calorie deficit, elements that corroborate the increase or decrease in energy reserves. The wrong energetic oscillation can lead to loss of muscle mass, bone mass, and possible hormonal disorders, compromising physical capacity and making it possible to put the individual's health at risk. ${ }^{7-9}$

A balanced diet is indispensable to ensure that practitioners of physical activity reach their goals, be they in physical, aesthetic, or quality of life. ${ }^{10}$ With the premise that training strategies fundamentally depend on their practitioners' dietary habits, understanding how nutrients work in the body becomes essential and a valuable aid to exercise programs developed in gyms. ${ }^{11}$ The current condition of society has inflicted on individuals an agitated way of life, making their subsistence precarious, and their dietary routines weakened. In this situation, some individuals practice strength training, often engage in most of their time with work or studies and often find it challenging to adapt their training to a food intake that sufficiently favors them achieving satisfactory results. ${ }^{7}$
However, there is a lack of understanding of what would be appropriate to consume, how and when to consume it, due to the lack of reliable information and adequate nutritional guidance..$^{10}$ Also, many feel the influence of friends, physical educators, and others who are not qualified for nutritional guidance and, finally, start developing eating habits and adherence to unconventional diets. ${ }^{12}$ Not least, the desire to achieve their goals in a short period has led many strength training practitioners to use dietary supplements indiscriminately, as many advertisements are promising short-term profits. ${ }^{7,10}$

This research objective was to analyze the nutritional knowledge of strength training practitioners who perform activities in a gym on the west side of the city of Rio de Janeiro.

\section{Material and methods}

Because this is a descriptive study, it presents descriptions of a specific audience's characteristics, raising opinions, and individual behaviors regarding their beliefs. Besides, the type of design of this research takes the form of a field study, taking into account the procedures adopted. ${ }^{13}$ The instruments used in this research were two closed questionnaires, to allow the subject/informant to express his ideas or opinions because the questions are predefined, in addition to collecting information in a relatively short time interval, in order to obtain information from the study population. ${ }^{14}$

The first questionnaire contained information that allowed the sample's profile to be traced, such as age, education, information on the nutritional orientation of respondents, use of diets, and nutritional supplements. For the assessment of nutritional knowledge, we used the questionnaire proposed by Bassit and Malverdi, ${ }^{15}$ containing nine objective questions about essential nutrition. According to the methodological procedure, this research presents a qualitative approach to the data, despite the possibility of providing quantitative information, aiming to discover the reality of the nutritional conduct adopted by the subjects participating in the sample. The sample consisted of 20 resistance training practitioners, of both sexes, aged between 16 and 45 .

As an attribute of inclusion in the sample, all components should have been practicing strength training for at least one year regularly. 
All participants became aware of the ethical aspects of the research and signed the Informed Consent Form. The participants, selected at random, answered the questions before practicing physical activity, and the objective of the research was clarified. Before answering the questionnaire, the participants signed the Free and Informed Consent Form. The data received statistical treatment. To the questionnaire data, we assign the value of 1 (one) point to each question answered correctly, with 9 points. Below 5 points, it indicates low nutritional knowledge below 5 to 6.9 indicates moderate nutritional knowledge and between 7 to 9 points, indicates high nutritional knowledge. The results received a percentage frequency obtained by descriptive statistics, with a comparison of means and standard deviation.

\section{Results}

Of the 20 respondents, $60 \%$ are men $(\mathrm{n}=12)$ and $40 \%$ women $(\mathrm{n}=8)$, the average age is $27.05 \pm 9.37$, with an average age for women of $29.62 \pm 7.39$ and $25.33 \pm 10.19$ for men. The level of education of the participants was $60 \%(n=12)$ with high school, $35 \%(n=7)$ with higher education and $5 \%(\mathrm{n}=1)$ with only elementary school. We observed that $57 \%$ of women and $43 \%$ of men had higher education (undergraduate). Regarding the average level of education, $67 \%$ are men, and $37 \%$ are women. The research analyzed whether the respondents had already obtained nutritional guidance, $60 \%(\mathrm{n}=12)$ obtained some nutritional guidance, while $40 \%(n=8)$ did not obtain any form of nutritional guidance. The data indicate that the proportion is $50 \%$ for men and women who have already had some nutritional guidance. We also checked the educational profile of respondents with a high school level of education, $58 \%$ had no guidance, while $42 \%$ had already received guidance. Regarding those with higher education (undergraduate), $100 \%$ of those surveyed stated that they received guidance. Of the respondents who had nutritional guidelines, the research points out that only $25 \%(n=3)$ were guided by nutritionists, while $50 \%(\mathrm{n}=6)$ guided by physical educators and doctors guided the remaining $25 \%(\mathrm{n}=3)$. In addition, $40 \%(\mathrm{n}=8)$ have already followed a diet, with $37 \%(n=3)$ being prescribed by nutritionists, $25 \%(\mathrm{n}=3)$ were guided by nutritionists, while $50 \%$ $(n=6)$ were guided by physical educators, and the remaining $25 \%$ $(n=3)$ were guided by doctors. In addition, $40 \%(n=8)$ have already followed a diet, $37 \%(\mathrm{n}=3)$ being prescribed by nutritionists, $25 \%$ $(\mathrm{n}=2)$ by doctors and $38 \%(\mathrm{n}=3)$ by unconventional means. Only $13 \%(n=1)$ continue to follow a diet, legally, by a nutritionist. When asked if they had already used nutritional supplements, $90 \%(\mathrm{n}=18)$ of the respondents answered yes, of which $61 \%(n=11)$ had already followed some nutritional instruction, and $55 \%(n=9)$ continue to use food supplements. Furthermore, 39\% $(n=7)$ surveyed who have never received guidance on nutritional issues, of which $36 \%(n=4)$ continue to use supplements.

The main reasons for the consumption of nutritional supplements were $67 \%(n=12)$ for weight gain, $17 \%$ to compensate for possible nutritional deficiencies, $11 \%$ for weight gain, and $5 \%(\mathrm{n}=1)$ physical performance. Of the respondents who used supplements, 33\% $(n=6)$ used them on their own, $28 \%(n=5)$ attributed the use to physical educators, $22 \%(n=4)$ to someone they knew and only $17 \%(n=3))$ to the nutritionist. More than half $60 \%(n=12)$ of those surveyed think it is possible to meet the nutritional needs demanded by exercise without using dietary supplements. But $30 \%(n=6)$ think it is unlikely, $5 \%(\mathrm{n}=1)$ said no and $5 \%(\mathrm{n}=1)$ did not know how to answer. Also, $95 \%(n=19)$ think that the use of food supplements without proper guidance can be harmful to health, and 5\% $(\mathrm{n}=1)$ did not know how to answer. About the basic nutrition questionnaire, we observed that $35 \%$ $(\mathrm{n}=7)$ had low nutritional knowledge, $35 \%(\mathrm{n}=7)$ moderate nutritional knowledge, and 30\% $(\mathrm{n}=6)$ high nutritional knowledge. We found that the sample's total mean was $5.25 \pm 1.94$, presenting a moderate nutritional knowledge level. Regarding the level of education, the average for those surveyed with high school education was $4.6 \pm 1.87$ (low nutritional knowledge) and the average for those surveyed with higher education training at $6 \pm 1.77$ (moderate nutritional knowledge). Regarding gender, showing that the mean for men was $5.08 \pm 1.60$, and for women, it was $5.5 \pm 2.23$.

\section{Discussion}

There was a subtle male predominance in the practice of strength training. The results of this study are similar to the studies made by Bueclher and Rossi ${ }^{16}$ and Schmitz and Campagnolo. ${ }^{17}$ This research corroborates the socio-political study by Costa, ${ }^{18}$ who observed that the supremacy of strength training practitioners is male, aged between 16 and 24, especially young people from high school and higher. Regarding the sample's education level, there was a more significant number of practitioners with secondary education, reaching $25 \%$ more than those with higher education. Considering that the respondents are living in a neighborhood located in the west zone of the municipality of Rio de Janeiro, the result found matches the data presented by Silva and Gamarski, ${ }^{19}$ who describe the region as having the lowest average level of schooling in the world. Municipality of Rio de Janeiro, around $5 \%$, while the average for the municipality of Rio de Janeiro is $18.2 \%$.

Also, reinforcing the result indicated in the study by Reis, Mello, and Confortin, ${ }^{20}$ the information obtained indicates that the education of women is higher than that of men. Most of the participants who obtained nutritional indication received from physical educators, followed by indication from friends or acquaintances, and the others sought information on their own. The findings are similar to those of the research by Ramos and Navarro, ${ }^{21}$ in which they concluded that nutritionists never recommended any guidance to $85 \%$ of those surveyed; this result points to a probable lack of nutritional instruction, and something very similar is in the study by Silveira et al. ${ }^{22}$

Considering that the Physical Education professional studies nutrition just enough to give basic instruction, he must advise on each professional's attributions and, in this case, the nutritionist's indication. When the Physical Education professional exercises the function of instructing on nutrition to the point of prescribing food, it violates professional ethics. The Law No. 9,696 / 98 regulates the profession; it says in its article 3: "Physical education can: coordinate, plan, program, supervise, optimize, direct, organize, evaluate and execute works, programs, plans, and projects, in addition to providing services audit, consultancy, and advisory services, conduct specialized training, participate in multidisciplinary and interdisciplinary teams and prepare technical-scientific and pedagogical reports, all in the areas of physical activities and sport".

At no time does anything related to food, diet, or supplementation be mentioned. Article 4 of Law 8234/91, which regulates the profession of nutritionists, states: "The following activities are also attributed to nutritionists, as long as they are related to human food and nutrition: [...] VII - prescription of nutritional supplements, necessary to supplement the diet".

As for the nutritional guidance provided by doctors, given that it was registered in the present research, it will not always be a satisfactory possibility, as the study by Boog $^{23}$ reports that there is some difficulty encountered by them, regarding the correlation between theory and practice. 
The criteria used by doctors are offered when there is already a clinical problem, such as hypertension, diabetes, or others. In a way, a nutritional intervention will not always respect biological needs and individualities. Scientific research ${ }^{20,24}$ have highlighted the frequent increase in the use of nutritional supplements, a fact also found in this study, with the finding that only $10 \%$ of the sample never used nutritional supplements and the significant portion of $90 \%(\mathrm{n}=18)$ of the sample used nutritional supplements. More than half $67 \%(\mathrm{n}=12)$, still use it without any legal recommendation from nutritionists. The high consumption of supplements without the proper professional indication of a nutritionist is a health risk. ${ }^{21,25-27}$ The same portion of those surveyed who still use supplements, responded to be aware that the use of nutritional supplements without proper guidance can be ineffective, as it is harmful to health.

The participants' behavior in this study is similar to the findings of the study by Goston. ${ }^{24}$ The reason why the search for qualified nutritional guidance is quite insignificant can be explained by the disparity between the purposes of practitioners and nutritionists. The nutritionists' primary objective is to promote quality of life, diverging from the main objectives of many strength training practitioners, which are aesthetics and physical performance. This statement by Felix ${ }^{28}$ contradicts the result found in the present research, being the biggest reason for the use of the nutritional supplement for $67 \%$ of those surveyed in this study: the increase in muscle mass. Concerning the levels of nutritional knowledge of the respondents, there was a percentage distributed among the three levels of classification of nutritional knowledge, used as evaluation criteria, with $35 \%$ $(\mathrm{n}=7)$ presenting low nutritional knowledge, 35\% $(\mathrm{n}=7)$ moderate nutritional knowledge and 30\% $(n=6)$ high nutritional knowledge. In general, the participants had moderate nutritional knowledge, since the total average was around 5.25 points (a score leveled to the range of moderate nutritional knowledge in the present study)

Regarding gender, there were no significant differences. However, as for the level of education, it was found that the participants who had a higher level had a higher average, around 6 points, compared to the participants who had a high level of education, who had an average of 4.6 points. Similar results are in others researchs, ${ }^{16,29,30}$ where it is possible to observe a correlation between the level of nutritional knowledge and level of education since respondents with higher levels of schooling showed better aspects regarding nutritional knowledge. This peculiarity is properly associated with the fact that a person's educational training period influences their perception of nutritional knowledge. ${ }^{16}$

\section{Conclusion}

It was possible to observe through the data that there is some concern about the respondents' part regarding their eating habits. However, there is an indiscriminate consumption of nutritional supplements, with the most consumed supplements being protein powders, which proves to be the typical artifice of those who prioritize aesthetic aspects. It is a worrying situation, considering that such an application should happen only when the individual's usual diet does not meet his nutritional needs. What the name of the product suggests together with the fact that the supplement is only a modified composition food, that is, it is a natural compound that is intended to provide nutrients in order to complement them in a balanced diet.

However, nutritional needs need clinical tests, such as biochemical screening, to be identified, reinforcing the idea of legal support to ascertain the real needs. We can also conclude that the interviewees have a moderate level of nutritional knowledge. More significant investment is needed in proposals that can intervene and influence the public's nutritional education in question. It is essential to include a nutritionist, especially a sports nutritionist, in addition to physical activity and food programs. Thus, personalized actions are recommended, such as the nutritionist's demand within sports establishments or even referral to such professionals, affirming their work together with the physical educator and public health actions regarding nutrition linked to physical activity. It is convenient to reach the specific public with actions aimed at improving the quality of information and actions that discuss theoretically and in practice, the role of the physical education professional in undergraduate courses.

\section{Acknowledgments}

The authors are thankful to the Universidade Salgado de Oliveira, Departament of Physical Activity Sciences and Augusto Motta University Center for providing financial assistance to carry out this study.

\section{Conflicts of interest}

There is no conflicts of interest.

\section{Funding}

None.

\section{References}

1. Forgiarini L. Adhesion of clients at the gym after applying a marketing strategy: a case study. UNESC. 2012.

2. Menon D, Dos Santos JS. Protein consumption by muscle-building practitioners who objectify muscle hypertrophy. Revista Brasileira de Medicina do Esporte. 2012;18(1):8-12.

3. Azevedo AMP, et al. Muscle dysmorphia: dietary and nutritional supplementation characteristics. ConScientiae Saúde. 2011;10(1):129137.

4. Segunda E, Anzuategui LSY, Frasson AC. Physical activity and nutrition: an interdisciplinary health program. The FIEP Bulletin. 2010;80(Special Edition).

5. Ciolac EG, Guimarães GV. Physical exercise and metabolic syndrome. Revista Brasileira de Medicina do Esporte. 2004;10(4):319-324.

6. Piaia CC, Rocha F, Do Vale GDBF. Nutrition in physical exercise and body weight control. Revista Brasileira de Nutrição Esportiva. 2007;1(4):40-48.

7. Adam BO, Fanelli C, Souza ES, et al. Nutritional knowledge of bodybuilders at a gym in the city of São Paulo. Brazilian Journal of Sports Nutrition. 2013; 2(2).

8. Sá JA. Food comparison between practitioners and non-practitioners of regular physical activity. Revista Brasileira de Nutrição Esportiva. 2012;6(32):126-130.

9. Zanetti GG, Carlos de Morais D, BrandaoDA, et al Influence of carbohydrate supercompensation on the vo2max of physically active subjects. Revista Brasileira de Nutrição Esportiva. 2010;4(21):268-275.

10. Souza VM, Navarro AC. The nutritional education of gym academies in Salvador-BA: food associated with physical exercise. Revista Brasileira de Nutrição Esportiva. 2011;5(25):51-61.

11. Oliveira GG, Liberali R, Coutinho VF. Food consumption profile of women attending a gym in Curitiba. SaBios:Revista Saúde e Biologia. 2012;7(3):74-85. 
12. Seron VD, Fernandes CAM. Influence of Nutritional Guidance on Body Composition of Bodybuilding Practitioners in the Municipality of Marialva - PR. Revista Saúde e Pesquisa. 2008;1(3):315-318.

13. Gil AC. Como elaborar projetos de pesquisa. São Paulo: Atlas; 2006.

14. Amaro AIP. Utilização de vídeo digital no trabalho laboratorial em ensino da Química:uma experiência no $12^{\circ}$ ano. 2007.

15. Bassit RA, Malverdi MA. Nutritional assessment of triathletes. São Paulo Journal of Physical Education. 1998;12(1):42-53.

16. Bueclher LO, Rossi L. Application of the nutritional knowledge scale to bodybuilders. Revista Brasileira de Nutrição Esportiva. 2011;5(27):236242 .

17. Schmitz JF, Campagnolo PDB. Characteristics of muscle dysmorphia in bodybuilders: association with food consumption. Brazilian Journal of Sports Nutrition. 2013;2(2):1-8.

18. Costa NCG. The construction of masculinity from bodybuilding. In: Annals of the IV National Seminar Sociology \& Politics: Plurality and Guarantee of Human Rights in the 21st Century; 2012 Sept 25-27. Brazil, Paraná; 2012.

19. Silva JPP, Gamarski EAB. Campo Grande: some considerations about its development. In:Annais XVI National Meeting of Geographers. Crisis, praxis and autonomy: spaces of resistance and hope, space for dialogue and practices; 2010 July 25-31. Brazil: Porto Alegre-RS; 2010.

20. Reis C, Mello NA, Confortin FG. Nutritional knowledge of users and non-users of dietary supplements in gyms in a city in the east of Santa Catarina. Esportiva. 2012;6(34):250-260.

21. Ramos DCC, Navarro F. Food and anthropometric profile of bodybuilders in the city of Brasilia. de Nutrição Esportiva. 20125;6(32):140-145.
22. Silveira CS, et al. Assessment of knowledge of basic nutrition and sports of physical education teachers in an academy in Aracaju/SE. Cadernos de Graduação - Ciências Biológicas e da Saúde. 2012;1(15):65-74.

23. Boog MCF. Public health nutritionist's role in promoting healthy eating. Revista Ciência \& Saúde. 2008;1(1):33-42.

24. Goston JL. Prevalence of the use of nutritional supplements among practitioners of physical activity in gyms in Belo Horizonte: associated factors. Faculdade de Farmácia da UFMG. 2008.

25. Pereira JMO, Cabrail P. Assessment of basic knowledge about nutrition of bodybuilders in an academy in the city of Recife. Revista Brasileira de Nutrição Esportiva. 2007;1(1):40-47.

26. Domingues SF, Marins JCB Use of ergogenic resources and food supplements by bodybuilders in gyms. Fitness \& Performance. 2007;6(4):218-226.

27. Fontes AMSA, Navarro F. Consumption of nutritional supplements by practitioners of physical activity in gyms in Sete Lagoas-MG. Revista Brasileira de Nutrição Esportiva. 2010;4(24):515-523.

28. Felix IRS. Assessment of knowledge of food sources and use of sports supplements among users of the Fitness Club gym in Guarulhos. Revista Brasileira de Nutrição Esportiva. 2011;5(27):230-235.

29. Nicastro H, Dattilo M, Rodrigues dos Santos T, et al. Nutrition knowledge scale application in professional and amateur track and field athletes. Revista Brasileira de Medicina do Esporte. 2008;4(3).

30. Dattilo M, Paula, Ana Paula K, et al. Nutritional knowledge and its association with the body mass index. Nutrire. 2009;4(1):75-84. 